Article

\title{
Investigation of a Novel Mechanical to Thermal Energy Converter Based on the Inverse Problem of Electric Machines
}

\author{
Lei Chen, Yulong Pei ${ }^{*}$, Feng Chai and Shukang Cheng \\ School of Eletrical Engineering and Automation, Harbin Institute of Technology, Harbin 150001, China; \\ hitchenlei@hit.edu.cn (L.C.); chaifeng@hit.edu.cn (F.C.); cskee@hit.edu.cn (S.C.) \\ * Correspondence: peiyulong@hit.edu.cn; Tel.: +86-451-8641-3611 \\ Academic Editor: Chunhua Liu \\ Received: 16 April 2016; Accepted: 30 June 2016; Published: 5 July 2016
}

\begin{abstract}
A novel converter that can directly transform electrical, wind, hydraulic and other types of mechanical energy into thermal energy is presented in this study. First, the thermal energy of the converter is classified and then calculated by a finite element method. The eddy current distribution in the stator of the converter is also discussed. Second, the temperature field of the converter is calculated using a boundary element method. Subsequently, a thermal power-temperature coupled calculation method is presented to calculate the actual thermal power and temperature of the converter. The characteristic curves of the actual thermal power and the increase in water flow temperature are then presented based on the calculation results. Lastly, an experimental system is built, the thermal power and temperature of the converter are measured and the experimental results and the analytical calculations are compared.
\end{abstract}

Keywords: converter; electric machine; permanent magnet; thermal energy; eddy current; temperature

\section{Introduction}

Thermal energy is one of the most important forms of energy used in both industrial production and normal daily living. The primary, most direct and simplest method to obtain heat is by collecting radiation from the sun. However, the extensive application of solar energy in providing heat is limited, due to the low energy density and discrepancies between collection time and use time [1]. Consequently, the combustion of fossil fuels, such as coal, oil and gas, remains as the more economical and practical method of providing heat [2]. Since the Industrial Revolution, fossil fuels have driven economic growth, particularly in developed countries. However, fossil energy has many disadvantages, such as having a low energy conversion efficiency, being non-renewable, and causing pollution and the greenhouse effect [3].

At present, considerable attention has been focused on novel thermal energy generation techniques that exhibit advantages such as high efficiency, zero-pollution, safety, and comprehensive use of clean energy [4]. Meanwhile, energy policies worldwide have encouraged the utilization of renewable energy sources (e.g., wind energy, geothermal energy, biomass and biofuels, and fuel cell technologies) [5-8]. Converting electric energy into thermal energy is apparently a clean and effective method to obtain heat. However, electric energy is not a primary energy; in fact, it has to be produced firstly from fossil energy, hydraulic energy, atomic energy, or some other form of mechanical energy, before being converted into thermal energy. Attempting to combine these two steps into one to provide a means to convert mechanical energy directly into thermal energy will require significant work.

An electric machine (EM) is used to convert fuel energy, hydraulic energy, atomic energy or other forms of mechanical energy into electric energy (the generator), or convert electric energy into 
mechanical energy (the motor) [9]. Losses are generated during these processes, including resistance or copper losses, core losses, mechanical losses, and additional losses [10]. In the forward problem that occurs in an EM, these losses should be reduced to improve energy-conversion efficiency, because all losses are converted into thermal energy, which increases the temperature of an EM and affects its performance [11]. Thinking inversely, however, we attempt to enhance losses in an EM to enable the EM convert all the input energy into thermal energy without producing mechanical or electric energy. That is, a novel converter can be developed based on the inverse problem of loss and temperature rise in the EM, which can sufficiently and effectively convert all the forms of input energy (e.g., electrical, wind, hydraulic and other types of mechanical energy) completely into heat.

Figure 1 shows the structure of the converter in both the axial and radial directions. Similar to traditional EMs (Figure 1A), the converter consists of a stator, a rotor, a shaft and permanent magnets (PMs). The stator and the rotor are made of solid steel, which differs from the laminated steel in EMs. The placement of the PMs is the same as that of a tangential magnetizing interior PM motor. The PMs are placed as insets in the rotor, and the polarity of adjacent PMs are opposite. When the rotor is rotated by other driving forces, which can be generated by wind, hydraulic and other forms of mechanical energy, a rotating magnetic field is produced in the gap, the stator, and the rotor. Then, eddy current power and hysteresis thermal power are generated in the stator, the rotor, and the PMs as a result of the effect of the rotating magnetic field. The mechanical thermal power in bearings, as well the frictional thermal power between water and the converter, is also generated through rotation. Water flows axially from the inlet to the outlet and through the gap; hence, all forms of thermal power are finally transmitted to the water (Figure 1B). The converter can be used to supply hot water and thermal power, particularly in the remote areas where electric energy may be unavailable but with possible access to wind energy and hydraulic energy.



(A)

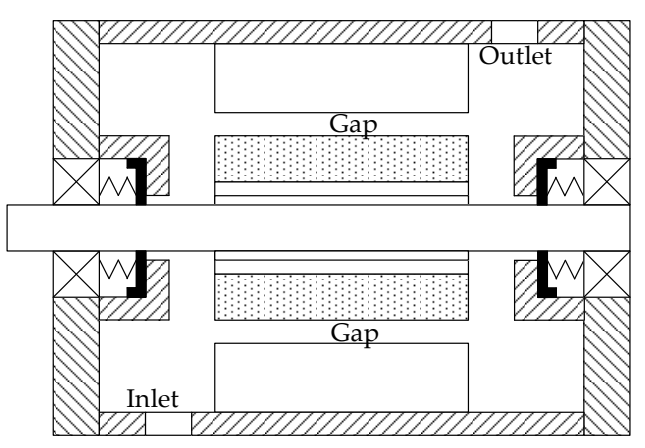

(B)

Figure 1. Structure of the converter: (A) axial direction and (B) radial direction.

The mechanism behind the proposed converter differs from that of the traditional induction heating technique. In the latter, the winding is supplied by an AC current to generate an eddy current in the metal to be heated. Therefore, resistance loss is unavoidable in the winding, and the efficiency of this technique is limited [12]. Several new induction heating techniques have been reported recently. Researchers from the Universities of Bologna, Padua and Roma [13-18] used a DC high-temperature superconductive (HTS) winding to produce a high-intensity DC magnetic field, and the billet to be heated was rotated in this field. Figure 2 shows the principle of this induction heating technique. This technique essentially uses an equivalent rotating magnetic field to generate eddy current. Lubin [19] applied a two-phase superconductive winding with two operating modes. The first mode is the same as the technique presented in [13-18]. In the second mode, the winding is supplied by a two-phase AC current with low frequency, and the billet remains stationary. During this mode, a rotating magnetic field is generated by the two phases of the windings supplied by a two-phase AC current. Figure 3 shows the configuration of this induction heater. The efficiencies of these new induction heating 
techniques are higher than those of traditional techniques because of the decrease in resistance loss. However, the manufacturing cost and energy consumption of HTS windings cannot be disregarded. Notably, current is essential in all aforementioned induction heating techniques; that is, the electric energy is essential. Therefore, these techniques can only operate in areas where electric energy is available.

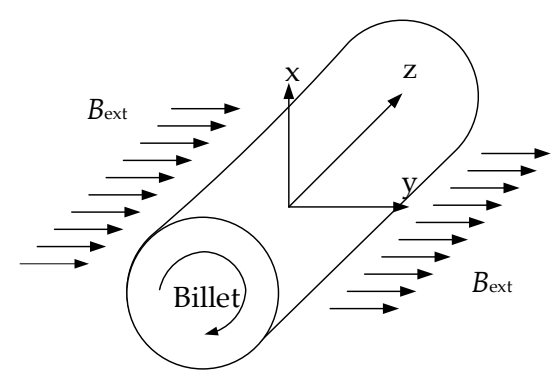

Figure 2. Principle diagram of the novel DC induction heating technique. $B_{\text {ext }}$ denotes the external DC magnetic field generated by the DC current in the windings.

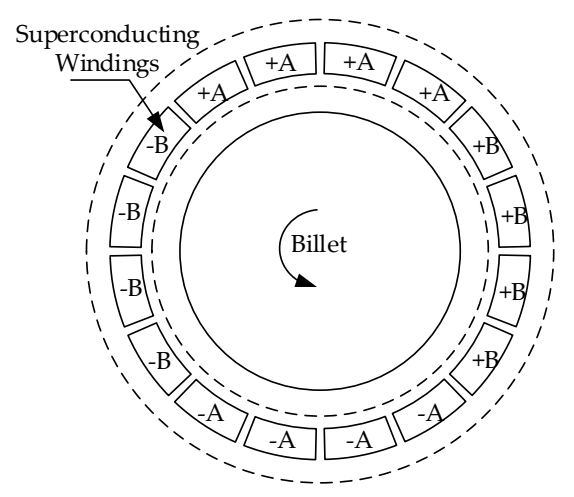

Figure 3. Cross section of two poles induction heater configuration. Symbols $+A,-A,+B$, and $-B$ indicate the phases and polarities of the current in the windings.

Takashi from Oita University presented a new induction heating device that used PMs [20]. Figure 4 shows the diagram of this heating device.

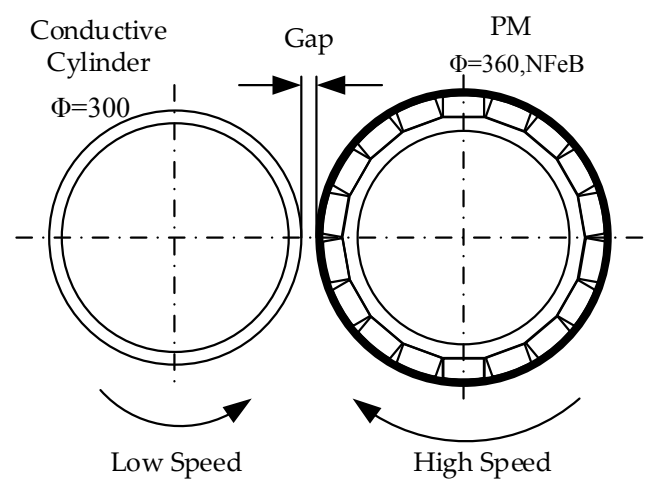

Figure 4. Structure diagram of the new induction heating device developed in Oita University.

The PMs rotate at a high speed to generate a rotating magnetic field in the gap, and the conductive cylinder rotates slowly. The powder or the other contents of the cylinder is heated by the thermal energy of the eddy current. This device has a simple structure and uses PMs to generate the rotating 
magnetic field instead of the windings. However, only a few PMs near the gap contribute to generating the thermal energy, and thus, the utilization of PMs is low in this device.

\section{Thermal Power Analysis}

The thermal power in the converter is firstly divided into mechanical and electromagnetic thermal power based on the classification of losses in EMs. For EMs with low power and low rotation speed, the proportion of mechanical losses to total power is considerably low [21]. To simplify the calculation process, we ignore the mechanical thermal power in the converter. Hereinafter, the term "thermal power" refers to "electromagnetic thermal power", unless specifically stated otherwise. Electromagnetic thermal power includes eddy current power and hysteresis thermal power. This section describes the calculation of the electromagnetic thermal power of the converter, and then discusses their distribution.

\subsection{Thermal Power Calculation}

By solving the electromagnetic field equations of the converter, the total thermal power $P$ of the converter is approximately calculated using Equation (1) [22]:

$$
P=\frac{8 n_{\mathrm{r}}^{\frac{3}{2}} M_{1}^{2} \sqrt{\frac{\sigma}{\mu}}}{15 \sqrt{30} \pi^{\frac{3}{2}}} \frac{26 \pi^{2} p^{\frac{1}{2}} D_{s 1}^{2} L^{2}-8.5 \pi^{4} p^{-\frac{3}{2}} D_{s 1}^{4}}{225 L e^{\frac{4 p \delta}{D_{s 1}}}}
$$

where $n_{\mathrm{r}}$ is the rotation speed, $M_{1}$ is the fundamental wave amplitude of the residual magnetization intensity, $\sigma$ is the conductivity, $\mu$ is the permeability, $p$ is the number of pole pairs, $D_{\mathrm{s} 1}$ is the inner diameter of the stator, $\delta$ is the gap length, and $L$ is the axial length

Equation (1) indicates the relationship between the parameters and the thermal power of the converter. A prototype, with a rated speed of $1500 \mathrm{rpm}$ and a rated power of $1.2 \mathrm{~kW}$, is designed based on Equation (1). The parameters of this prototype are listed in Table 1, and its photograph is provided in Figure 5.

Table 1. Parameters of the prototype.

\begin{tabular}{|c|c|c|}
\hline Parameters & Dimensions & Materials \\
\hline Stator outer diameter & $70 \mathrm{~mm}$ & \multirow{2}{*}{ Steel 20\# } \\
\hline Stator inner diameter & $58 \mathrm{~mm}$ & \\
\hline Gap length & $0.3 \mathrm{~mm}$ & $\mathrm{~N} / \mathrm{A}$ \\
\hline Rotor outer diameter & $57.4 \mathrm{~mm}$ & Steel 20\# \\
\hline Pole pairs & 9 & $\mathrm{~N} / \mathrm{A}$ \\
\hline PM magnetization length & $3 \mathrm{~mm}$ & \multirow{2}{*}{$\mathrm{N} 33 \mu \mathrm{H}$} \\
\hline PM width & $10 \mathrm{~mm}$ & \\
\hline Axial length & $55 \mathrm{~mm}$ & $\mathrm{~N} / \mathrm{A}$ \\
\hline
\end{tabular}

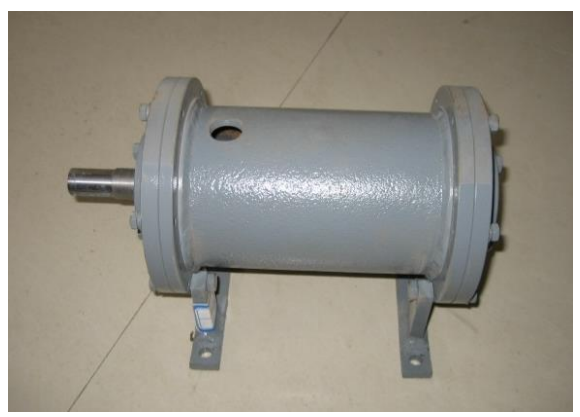

Figure 5. Photograph of the prototype. 
However, the electromagnetic field in the converter is complicated, and Equation (1) is only an approximate calculation equation. To calculate thermal power more accurately, the subsequent studies on thermal power are discussed based on the finite element method (FEM).

\subsubsection{Eddy Current Thermal Power}

By using time-step FEM [23], the eddy current density vector $J_{\mathrm{e}}$ in the converter is calculated by using Equation (2):

$$
\nabla^{2} A=-\mu J_{\mathrm{e}}
$$

where $\mu$ is the permeability $(\mathrm{H} / \mathrm{m})$, and $A$ is the magnetic vector potential.

From the integral form of the Ohm's law [24], the eddy current thermal power $p_{\mathrm{e}}$ of the converter is:

$$
p_{\mathrm{e}}=\frac{1}{\sigma} \int_{V} J_{\mathrm{e}} \cdot J_{\mathrm{e}} \mathrm{d} V
$$

where $\sigma$ is the conductivity $(\mathrm{S} / \mathrm{m})$, and $V$ is the area where eddy current occurs.

\subsubsection{Hysteresis Thermal Power}

Theory of hysteresis loss indicates that hysteresis thermal power per unit mass in the sinusoidal magnetic field is calculated using Equation (4) [25]:

$$
p_{\mathrm{h} 0}=K_{h} \cdot f \cdot B_{m}^{\alpha}
$$

where $K_{\mathrm{h}}$ and $\alpha$ are the coefficients that depend on the material, $f$ is the frequency of the magnetic field, and $B_{\mathrm{m}}$ is the amplitude of flux density. Steel \#20 is used in the prototype of the converter as the material of the stator and the rotor. The $K_{\mathrm{h}}$ of this steel is $0.045 \mathrm{~W} /\left(\mathrm{kg} \cdot \mathrm{Hz} \cdot \mathrm{T}^{2}\right)$, and $\alpha=2$ within the power frequency [26].

The magnetic field in the converter is rotating. To use Equation (4) in calculating hysteresis thermal power, we decompose flux density vector $\boldsymbol{B}$ into two orthogonal variables, namely, $B_{\mathrm{x}}$ and $B_{\mathrm{y}}$, and then translate them into sinusoidal variables using Fourier series expansion. Therefore, the hysteresis thermal power in the converter is calculated using Equation (5):

$$
p_{h 1}=\sum_{k=1}^{N} K_{h} \cdot k \cdot f_{k} \cdot\left(B_{k x m}^{\alpha}+B_{k y m}^{\alpha}\right)
$$

where $B_{k x \mathrm{~m}}$ is the flux density amplitude of the $k$-order magnetic field in the $x$ direction, $B_{k y m}$ is the flux density amplitude of the $k$-order magnetic field in the $y$ direction, and $f_{k}$ is the frequency of the $k$-order magnetic field.

\subsubsection{Calculation Result}

When the temperature is $10{ }^{\circ} \mathrm{C}$ and the rotation speed is $1500 \mathrm{rpm}$, the distributions of the eddy current and the magnetic flux of the prototype in a steady state calculated via FEM are shown in Figures 6 and 7, respectively. Eddy current density is higher in the inner surface of the stator and lower in its outer surface because of the skin effect of eddy current.

Eddy current power and hysteresis thermal power at different speed are shown in Figures 8 and 9, respectively. In Figure 8, the values of the eddy current thermal powers in the rotor and the PMs are considerably lower than that in the stator. The eddy current in the stator is generated by the main magnetic flux, which is established by the rotating PMs, whereas the eddy current in the rotor and the PMs is generated by the harmonic magnetic flux. This flux is low because the stator has no slots or windings as shown in Figure 7. 


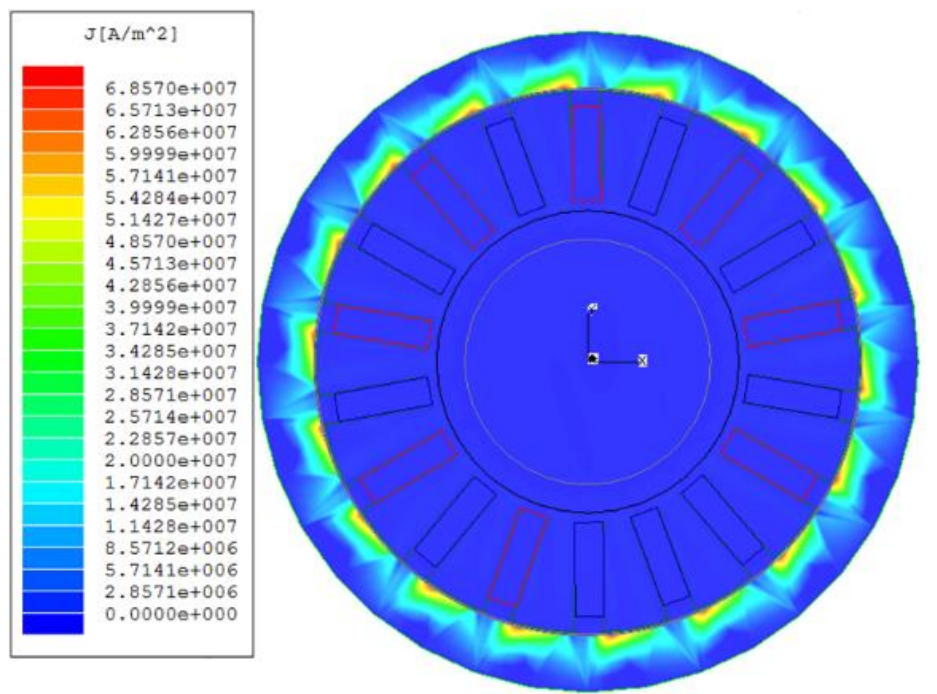

Figure 6. Distribution of eddy current density in a steady state when the rotation speed is $1500 \mathrm{rpm}$.

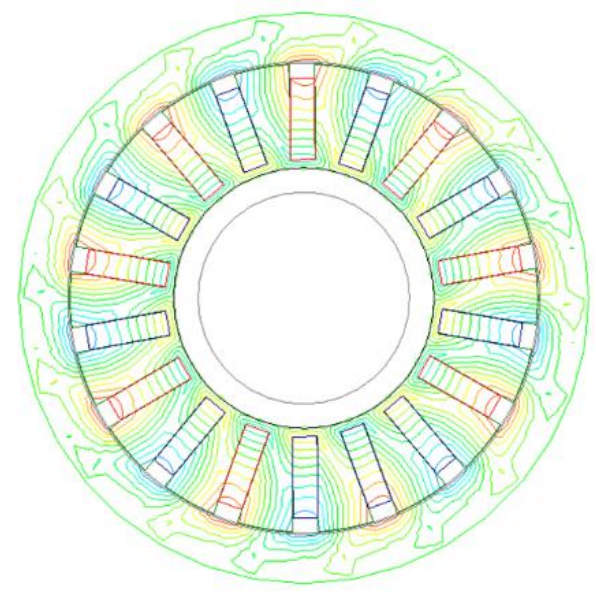

Figure 7. Distribution of magnetic flux in a steady state when the rotating speed is $1500 \mathrm{rpm}$.

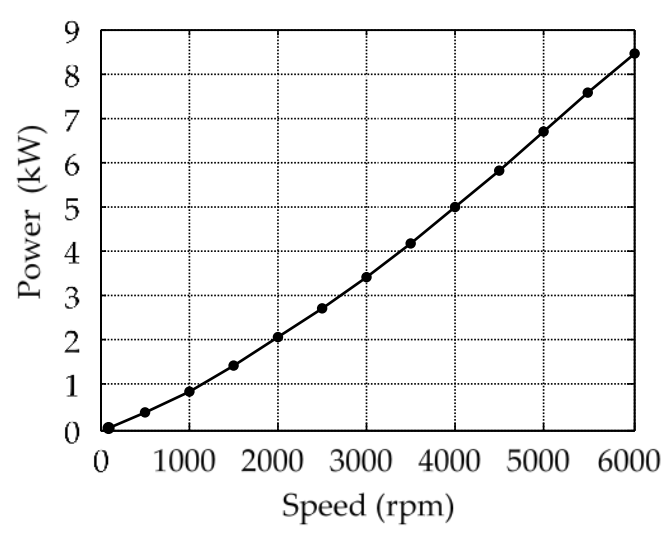

(A)

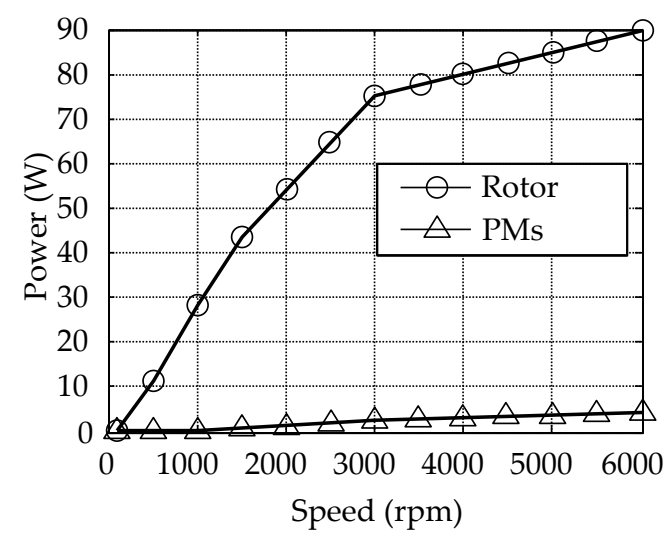

(B)

Figure 8. Calculated values of eddy thermal power in the: (A) stator; (B) rotor and PMs. 


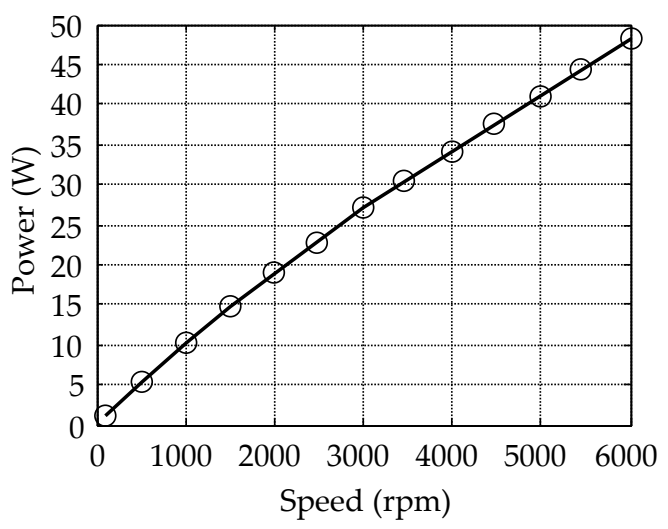

Figure 9. Calculated values of hysteresis thermal power.

Comparing Figure 9 with Figure 8A, hysteresis thermal power is considerably lower than the eddy current thermal power in the stator. However, in traditional EMs with laminated steel structure, hysteresis and eddy current losses are nearly equal [26,27]. The hysteresis effect is related to the amplitude of magnetic flux density, as well as the frequency and the characteristic of materials. These factors are the same in EMs and converters. However, compared with eddy current in EMs, which is restricted by the laminated structure of EMs, eddy current in the converter is considerably increased because of the solid structure of the converter.

As indicated by the calculation results of the thermal powers of the prototype and the related analysis, we should only consider eddy current thermal power in the following study of the converter. This consideration decreases the amount of computation but does not affect the correctness of the result. Moreover, Figure 8A shows that an approximately linear relationship exists between thermal power and rotation speed.

\subsection{Eddy Current Distribution}

The distribution of eddy current in the stator should be studied, not only because of the uneven distribution of eddy current in the stator (Figure 6), but also for the subsequent calculation of temperature.

To simplify the analysis, the stator is unfolded into a plate, as showed in Figure 10. Theoretically, the eddy current only occurs in axial direction $\left(J_{z}\right)$ and is generated by the magnetic field in the radial direction $\left(B_{y}\right)$. Assuming that all the variables are sinusoidal and permeability $\mu$ is constant, the current density in the inner surface of the stator is indicated by Equation (6), according to the theory of 2D travelling wave:

$$
J_{z}=J(y) \cos (\omega t-\lambda x)
$$

From Maxwell's equations, we obtain the differential equation of $J_{z}$ as follows:

$$
\frac{\partial^{2} J_{z}}{\partial x^{2}}+\frac{\partial^{2} J_{z}}{\partial y^{2}}=\sigma \mu \frac{\partial J_{z}}{\partial t}
$$

When Equation (6) is substituted into Equation (7), we obtain:

$$
\frac{\partial^{2} J}{\partial y^{2}}-J\left(\lambda^{2}+2 \omega \sigma \mu j\right)=0
$$

The solution for Equation (8) is:

$$
J_{z}=J_{\mathrm{m}} e^{-\beta y} \cos (\omega t-\lambda x-\gamma y)
$$




$$
\left\{\begin{array}{l}
\omega=2 \pi f=2 \pi n p / 60 \\
\beta=R \cos \varphi \\
\gamma=R \sin \varphi \\
R^{4}=\lambda^{4}+4 \alpha^{4} \\
\tan 2 \varphi=2 \alpha^{2} / \lambda^{2} \\
\lambda=\pi / \tau \\
\alpha=\sqrt{\sigma \mu \omega / 2}
\end{array}\right.
$$

where $\tau$ is the pole pitch (m), $n$ is the rotating speed (rpm), $p$ is the number of pole pairs, $J_{\mathrm{m}}$ is the amplitude of the current density on the inner surface of stator $\left(\mathrm{A} / \mathrm{m}^{2}\right)$, and $\omega$ is the angular frequency of rotation $\left(\mathrm{s}^{-1}\right)$.

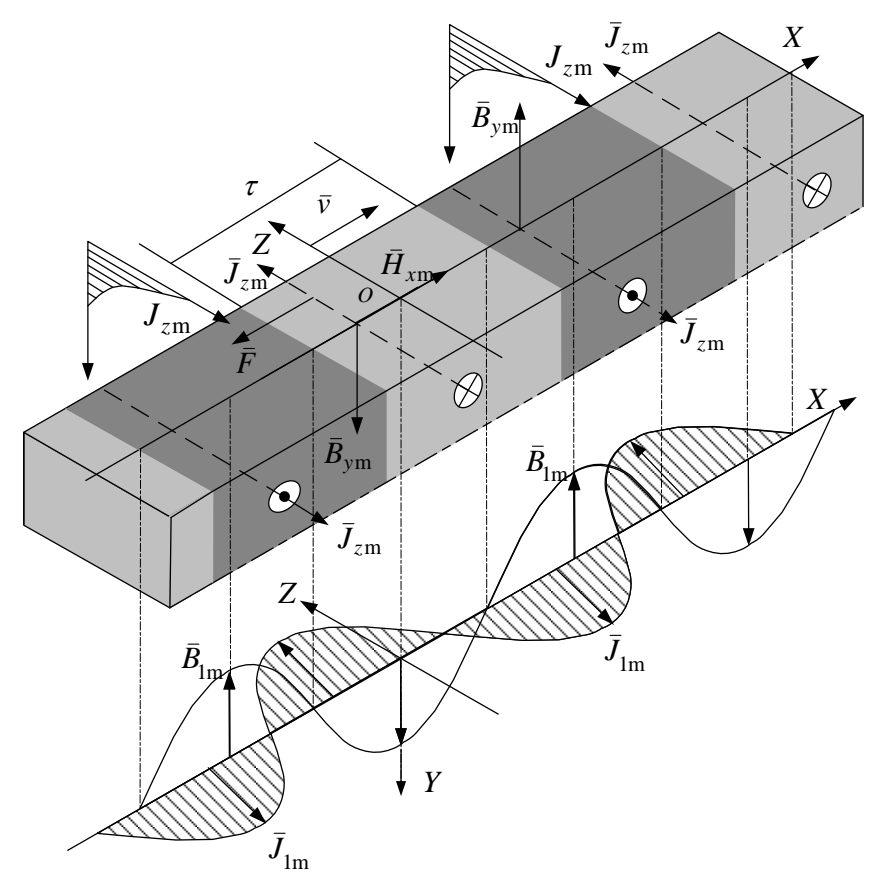

Figure 10. Unfolding diagram of the stator for the mathematical model of eddy current. $X, Y$, and $Z$ are circumferential, radial, and axial directions respectively; $J_{z \mathrm{~m}}$ is the amplitude of eddy current in the axial direction; $\tau$ is the pole pitch; $v$ is the speed; $B_{y \mathrm{~m}}$ is the amplitude of flux density in the radial direction; $B_{1 \mathrm{~m}}$ is the amplitude of the fundamental wave of flux density; and $J_{1 \mathrm{~m}}$ is the amplitude of the fundamental wave of eddy current density.

The rotating angular frequency $\omega$ is relatively high within the speed range of the converter. That is $2 \alpha^{2}>>\lambda^{2}$. Hence, Equation (9) is changed as follows:

$$
J_{z}=J_{m} e^{-\alpha y} \cos (\omega t-\lambda x-\alpha y)
$$

As shown in Equation (11), the rate between the amplitude of current density at the position where $y=2 / \alpha$ (i.e., where radial distance to the gap is $2 / \alpha$ ) and at the inner surface of the stator is only $1 / e^{2}$. Moreover, as indicated in Equation (3), the rate of eddy thermal power is only $1 / e^{4}$ (approximately 1.83\%). Hence, we assume that eddy current thermal power is only distributed in the area where its radial distance to the gap is less than $2 / \alpha$. 


\section{Temperature Calculation}

\subsection{Temperature Field Calculation}

The heat exchange process that occurs in the converter is mainly convection between water and the converter. In general, the convection problem can be solved via three methods: solving temperature and fluid field equations, using empirical equations based on experiments, and applying numerical analysis methods. The analytical solutions for the temperature and fluid field equations are highly complicated, or even impossible to realize. Only a few referential empirical equations can be used because of the new structure of the converter. Therefore, using the numerical analysis method to calculate the temperature field in the converter is practical. The boundary element method (BEM) is one of the most effective numerical analysis methods for calculating convection problems; it can also be used to calculate the heat transfer problem in other areas of the converter [28].

The temperature field calculation model is shown in Figure 11. Half of the radial section of the converter is used as the temperature calculation model given the symmetry of the converter. The model is divided into the stator, rotor, gap, PM, and heating areas. The following assumptions are then made: (1) The flow rate of water is constant; (2) The outer interfaces of converter are all adiabatic; (3) Thermal power is distributed evenly throughout the heating area, and the radial length of the heating area is $2 / \alpha$ according to the analysis in Section 2.2; (4) The effect of the rotating rotor on convection is ignored.

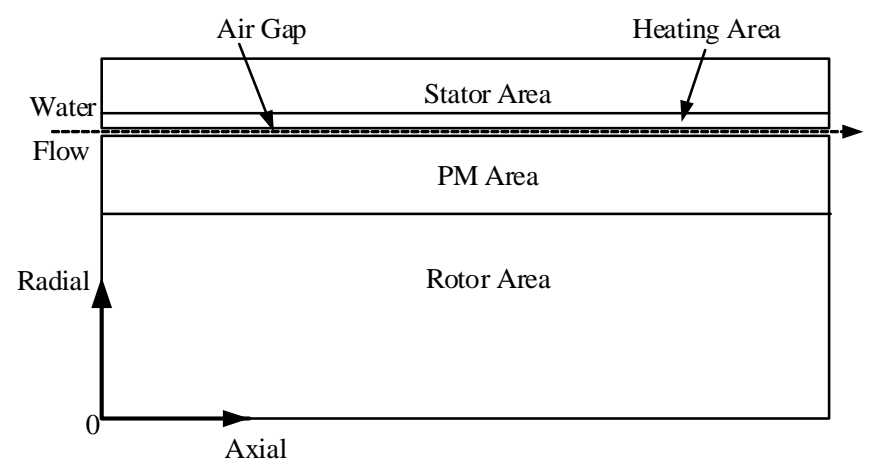

Figure 11. Calculation model of the temperature field.

The temperature distribution calculated using BEM is shown in Figure 12 when the rotation speed of the prototype is $1500 \mathrm{rpm}$, the initial temperature is $10^{\circ} \mathrm{C}$, and the water flow speed is $0.8 \mathrm{~m} / \mathrm{s}$.

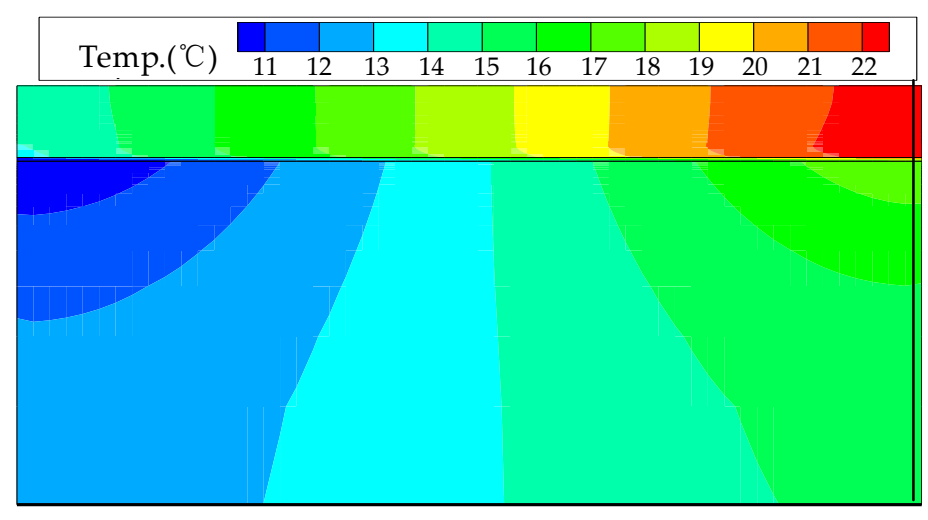

Figure 12. Temperature distribution of the prototype. 
As shown in Figure 12, heat in the converter is transmitted both along the axial and radial directions. Water flows along the axial direction, and its temperature increases gradually because of the heat exchange between water and the converter. Meanwhile, the heat generated in the stator is partly transmitted to the excircle of the stator; it is also transmitted through gap to the internal section of the rotor. Figures 13 and 14 show the distribution of temperature along the axial and radial directions, respectively.

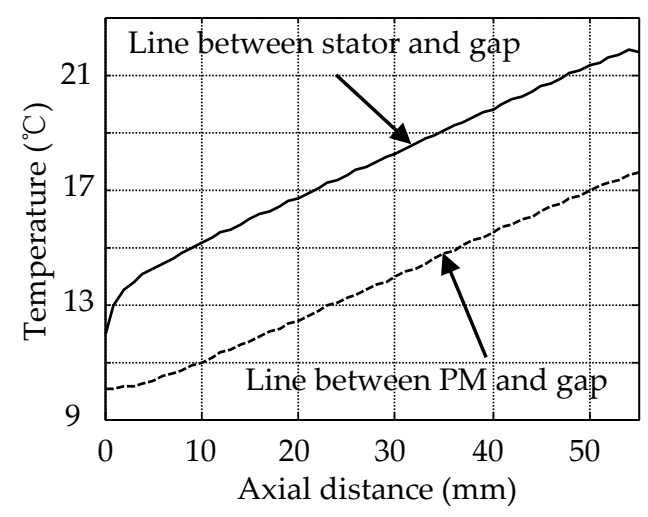

Figure 13. Temperature curves along the axial direction.

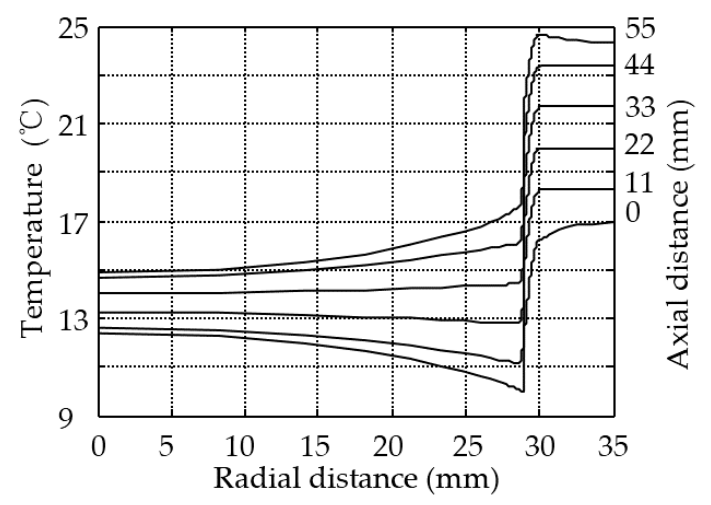

Figure 14. Temperature curves along the radial direction.

Figure 13 indicates the temperature on the lines between the stator and the gap and between the PM and the gap. Temperature linearly increases along the two lines because water flows along the axial direction and its temperature gradually increases.

Figure 14 indicates the temperature on six radial lines. The axial distances of the six radial lines to the origin are $0,11,22,33,44$, and $55 \mathrm{~mm}$. Temperature changes rapidly in the gap because of the convection between water and the converter. However, temperature changes slowly in the stator, rotor, and PM areas. The temperature distributions on these radial lines are opposite in the inlet and outlet sides. In the inlet side, temperature is decreased from the rotor to gap and increased from gap to stator. In the outlet side, the temperature is increased from the rotor to the gap and decreased from the gap to the stator. Overall, the temperature distribution along the axial direction is symmetrical to the middle section of the radial direction.

Notably, the temperature of the PMs is considerably lower than the Curie temperature, and the highest temperature point is located in the stator. Therefore, the PMs will not be demagnetized during operation. 


\subsection{Thermal Power-Temperature Coupled Calculation Method}

The thermal power and temperature calculated in Sections 2.1 and 3.1 are actually initial values. When the converter operates, its temperature will be gradually increased, and its thermal power will change because some characteristic parameters of the material change with temperature. If the flow speed of water and the rotation speed of the converter are constant, then the converter and water will achieve thermal balance. The thermal power and temperature of the converter in the thermal balanced state are actual values.

The changes in remanence and coercivity of the PM with temperature will directly change the magnetic flux of the converter and affect the thermal power. Equation (3) shows the change in conductivity also directly affect the thermal power.

Regardless of irreversible loss in the PM, its remanence and coercivity in different temperatures can be calculated using Equation (12) [29]:

$$
X_{t 1}=X_{t 0}\left[1-\frac{\alpha_{X}}{100}\left(t_{1}-t_{0}\right)\right]
$$

where $X$ is the remanence $(\mathrm{T})$ or coercivity $(\mathrm{A} / \mathrm{m}), \alpha_{X}$ is the temperature coefficient of remanence and coercivity $\left({ }^{\circ} \mathrm{C}^{-1}\right), t_{0}$ is the room temperature, and $t_{1}$ is the calculated temperature. Similarly, the conductivity of each temperature can also be calculated using Equation (12).

To calculate the actual values of thermal power and temperature, a thermal power-temperature coupled calculation method is presented, as shown in Figure 15. First, we estimate and provide the initial average temperature of the stator and the PM. Then, thermal power is calculated via FEM, as mentioned in Section 2.1, according to the electromagnetic parameters of the initial temperatures. Second, the temperature field is calculated via BEM, and the calculated temperatures of the stator and the PM are compared with the initial values. The thermal powers should be recalculated again with the calculated temperatures of the stator and the PM until the difference in temperature $\Delta T$ between two calculations is less than a certain small value $\varepsilon$. In the following calculation, $\varepsilon$ is set as 0.001 .

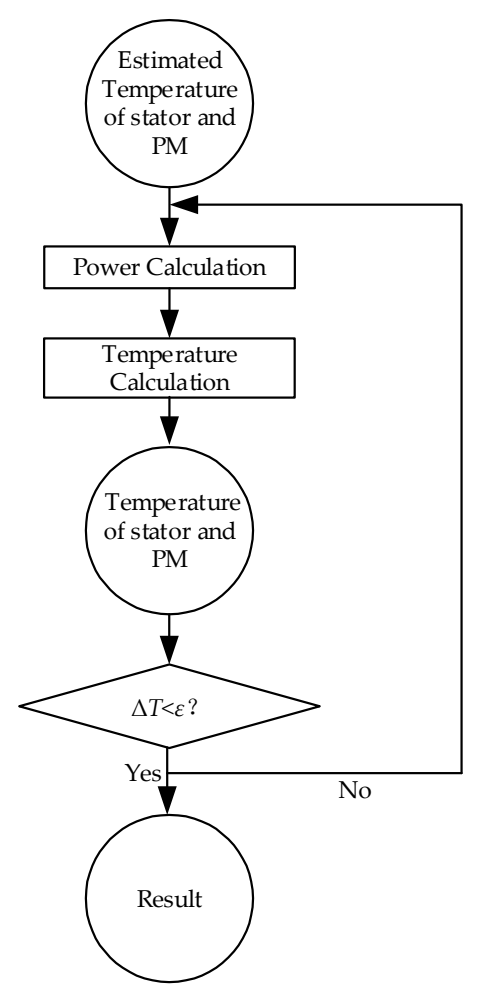

Figure 15. Flowchart of the thermal power-temperature coupled calculation. 


\section{Operating Characteristic of the Converter}

The decreasing rate between the initial and actual thermal power $\Delta P$ is calculated using Equation (13):

$$
\Delta P=\frac{P_{0}-P_{\mathrm{a}}}{P_{0}}
$$

where $P_{0}$ is the initial thermal power and $P_{\mathrm{a}}$ is the actual thermal power.

We calculate a series of rate curves of the prototype at different initial power and flow speed values, as indicated in Figure 16. This figure shows that the rate is lower when flow speed is higher and initial power is lower; this relationship is affected by temperature increase. A lower rate, that is, actual power is closer to initial power, indicates that the heat transfer performance of the converter is better.

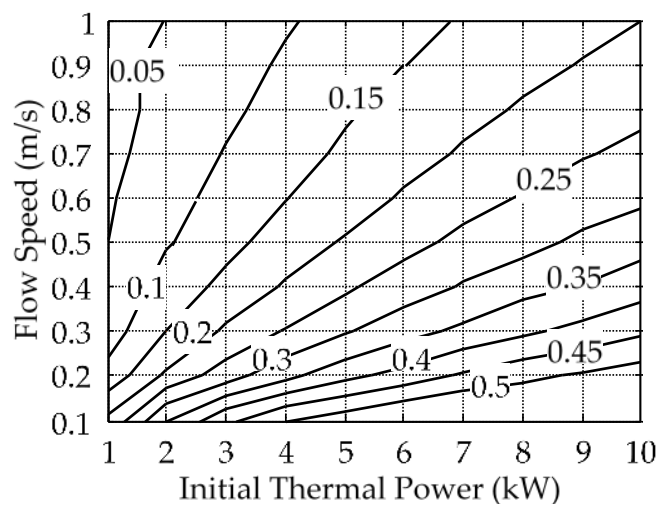

Figure 16. Rate at different flow speed and initial thermal power value.

Figure 17 shows the actual thermal power curves of the prototype, when flow speed and initial thermal power are changing. The equipotential lines in Figure 17 are the thermal power curves (unit: $\mathrm{kW}$ ). Actual power is close to initial power when flow speed is higher and initial power is lower. In such area, actual power remains nearly constant when flow speed is changing; this condition is suitable for a constant power output. Figure 17 shows the actual thermal power characteristic of the converter, which can be used to control its thermal power.

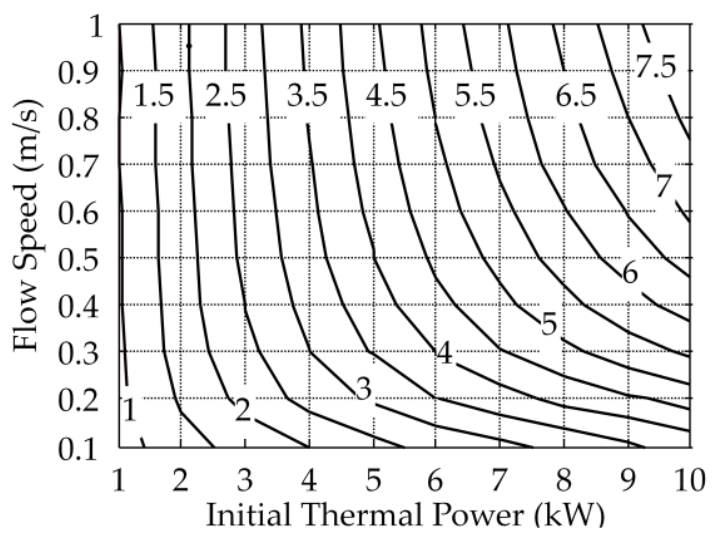

Figure 17. Actual thermal power curves.

Following the energy conservation law, the temperature increase of water flow $\Delta T_{\mathrm{w}}$ is calculated using Equation (14):

$$
\Delta T_{\mathrm{w}}=\frac{P_{\mathrm{a}}}{v S_{\text {gap }} \rho_{\mathrm{w}} C}
$$




$$
S_{\text {gap }}=\frac{\pi\left(D_{s 1}^{2}-D_{r 2}^{2}\right)}{4}
$$

where $v$ is the flow speed $(\mathrm{m} / \mathrm{s}), S_{\text {gap }}$ is the section area of the gap $\left(\mathrm{m}^{2}\right)$ calculated using Equation (14), $\rho_{\mathrm{w}}$ is the density of water $\left(\mathrm{kg} / \mathrm{m}^{3}\right), C$ is the specific heat of water $\left(\mathrm{J} /\left(\mathrm{kg} \cdot{ }^{\circ} \mathrm{C}\right)\right), D_{\mathrm{s} 1}$ is the inner diameter of the stator $(\mathrm{m})$, and $D_{\mathrm{r} 2}$ is the outer diameter of the rotor $(\mathrm{m})$.

The equipotential lines in Figure 18 are the temperature increase curves (unit: ${ }^{\circ} \mathrm{C}$ ). These curves indicate when temperature increase is lower, the operating area of the converter is lager, thereby providing more values of flow speed and initial thermal power to choose from when the required temperature increase is lower. Figure 18 indicates the actual temperature increase characteristic of the converter, which can be used to control its temperature increase.

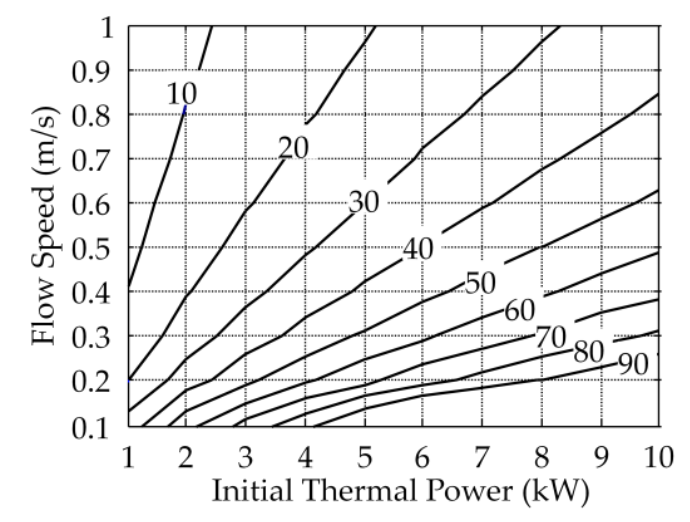

Figure 18. Temperature incease curves.

During the operation of the converter, the adjustable input variables are rotation speed and flow speed. The analysis in Section 2.1.3 indicates that the relationship between initial thermal power and rotation speed is approximately linear. Therefore, Figures 17 and 18 indicate the control characteristic of the converter, which provides the relationship between the input and output variables (actual thermal power and temperature increase of water, respectively) of the converter.

\section{Experiments}

\subsection{Experimental System}

The structural diagram and photographs of the experimental system are shown in Figure 19. The prototype is rotated by a motor, and the motor is driven by a controller, hence, the prototype can operate at different speeds. Water flows into and is stored in a homothermal tank, and thus the temperature of the water flowing into the prototype is constant. A pump is used to control the speed of the water flowing though the prototype and the pipes. The prototype and the pipes are wrapped with an insulation layer to ensure that nearly no heat exchange will occur between the prototype and its surroundings. Temperature sensors are placed in the inlet, the outlet, and test points A and B in the stator. The positions of points A and B are shown in Figure 20. Point A is located near the inner surface of the stator, and its radial distance to the inner surface is $0.5 \mathrm{~mm}$. By contrast, point $\mathrm{B}$ is located near the outer surface of the stator, and its radial distance to the outer surface is $0.5 \mathrm{~mm}$. Both points are located in the center of the axial direction. A flow flux sensor is placed in the pipe to measure the flow speed of water. A speed and torque sensor is placed on the shaft between the motor and the prototype. All the measured values are transmitted into a computer via a data acquisition card during the experiment. 


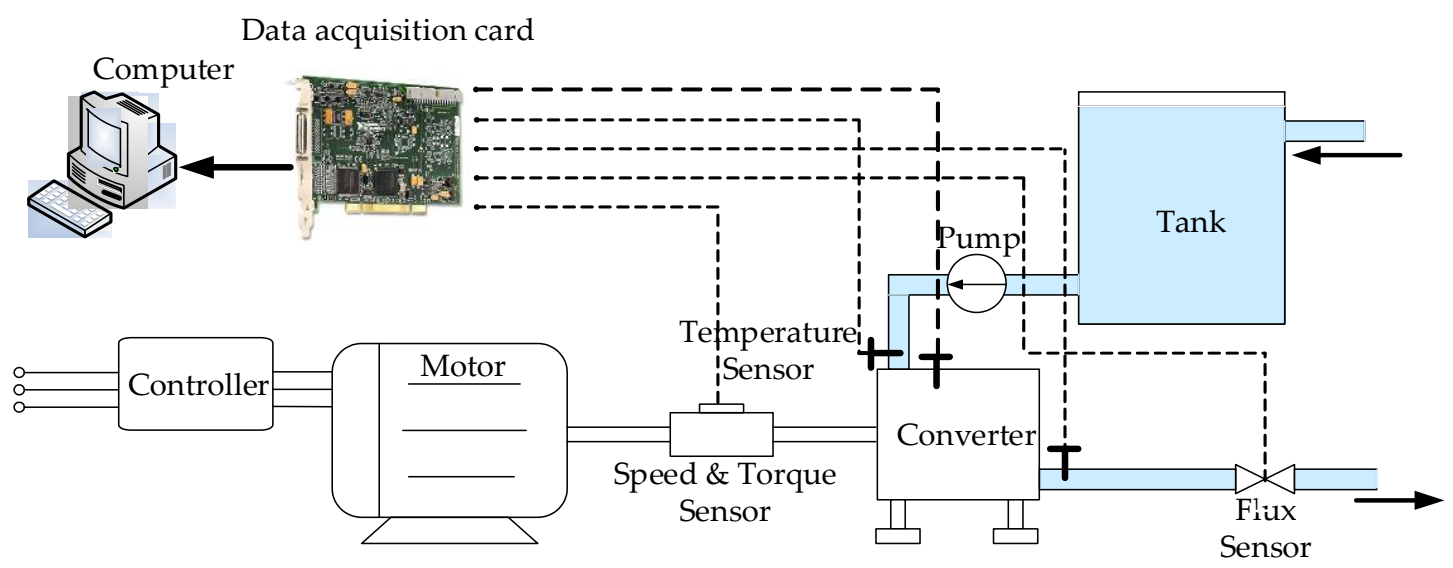

(A)

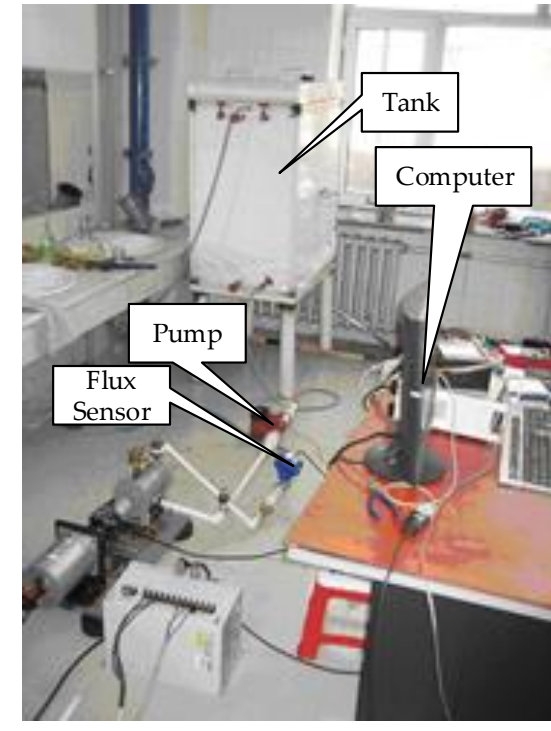

(B)

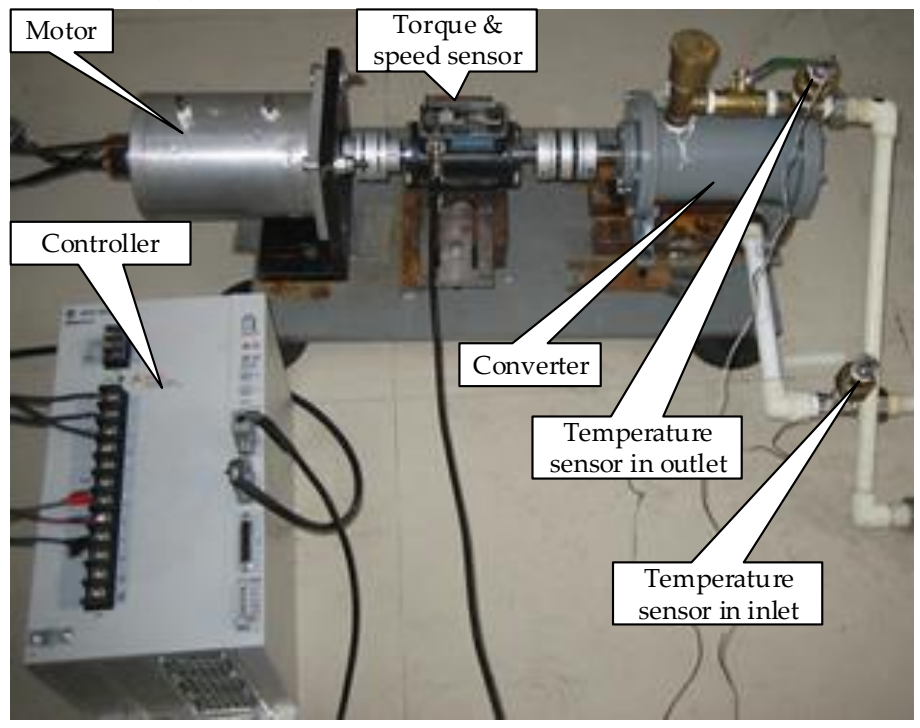

(C)

Figure 19. Experimental system. (A) Structural diagram; (B) photograph of the entire system; (C) photograph of the system near the converter. To display the system clearly, the insulation layer wrapped around the converter and the pipes were removed when these pictures were taken.

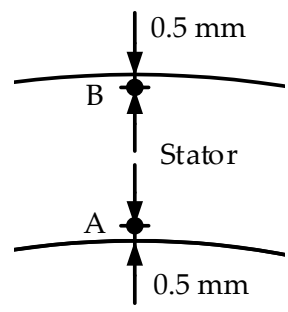

Figure 20. Diagram of the positions of test points A and B.

Before the prototype rotates, the pump starts and the homothermal water flows through the prototype at a constant speed. When the temperature of each sensor has remained constant for a certain period, we deem that the prototype is in a thermal balanced state, and the temperature of each part of the prototype is equal to the temperature of water. Then, the prototype is rotated by the motor at a certain speed. The output power of the motor, which is equal to the input thermal power of the prototype, is tested using the speed and torque sensor. Temperature and flow speed are also measured using corresponding sensors. Lastly, when the temperatures and torque have remained constant for 
a certain period, we deem that the prototype has again achieved a thermal balanced state, and the experiment is completed.

We use the variable of flow speed $l(\mathrm{~m} / \mathrm{s})$ in the calculation, but the measured value is flow rate $Q$ $\left(\mathrm{m}^{3} / \mathrm{h}\right)$. Given the conservation of the flow flux of water in the system, the flow speed in the gap is calculated using Equation (16):

$$
l=\frac{Q}{3600 S_{\text {gap }}}
$$

During the calculation, we assume that no heat exchange occurs between the converter and its surroundings; hence, the calculated thermal power should correspond to the measured input thermal power. The measured input thermal power of the converter $P_{\text {in }}$ is calculated using the measured values of the input torque and rotation speed as shown in Equation (17):

$$
P_{\text {in }}=\frac{2 \pi}{60} T n
$$

where $T$ is input torque (Nm), and $n$ is rotation speed (rpm).

The output thermal power $P_{\text {out }}$ is the thermal power transmitted into water flow, which is calculated using Equation (18):

$$
P_{\mathrm{w}}=\frac{\left(T_{\text {out }}-T_{\text {in }}\right) \rho_{\mathrm{w}} Q C}{3600}
$$

where $T_{\text {out }}$ and $T_{\text {in }}$ are measured temperatures at outlet and inlet, respectively $\left({ }^{\circ} \mathrm{C}\right) ; Q$ is the measured flux of water flow $\left(\mathrm{m}^{3} / \mathrm{h}\right) ; \rho_{\mathrm{w}}$ is the density of water $\left(\mathrm{kg} / \mathrm{m}^{3}\right)$, and $C$ is the specific heat of water $\left(\mathrm{J} /\left(\mathrm{kg} \cdot{ }^{\circ} \mathrm{C}\right)\right)$.

Output thermal power is always lower than input thermal power given that a small amount of heat is still exchanged between the converter and its surroundings even if the prototype and the pipes are wrapped with an insulation layer during the experiment. Energy conversion efficiency $\eta$ is the ratio of $P_{\text {out }}$ to $P_{\text {in }}$, and is calculated using Equation (19):

$$
\eta=\frac{P_{\text {in }}}{P_{\text {out }}} \times 100 \%
$$

\subsection{Results and Discussion}

Figure 21 shows the measured curves of flow flux, temperature, torque, rotation speed, and thermal power when the temperature of water in the inlet is $10^{\circ} \mathrm{C}$. Flow flux is $0.157 \mathrm{~m}^{3} / \mathrm{h}(0.8 \mathrm{~m} / \mathrm{s})$ and rotation speed is $1500 \mathrm{rpm}$. These values remain constant during the experiment. The temperature of inlet also remains constant during the experiment. By contrast, the temperature of outlet, point $\mathrm{A}$ and point $\mathrm{B}$, as well as the torque initially increase rapidly and then tend to remain constant.

The power of the converter is initially decreased and then tends to remain constant (Figure 21E). As the converter operates, its temperature increases (Figure 21B), and thus, the remanence and the coercivity of the PMs decrease, whereas the conductivity of the stator increases. Finally, thermal power is decreased because of these two factors. The prototype achieves a thermal balanced state given that the rotation speed of the converter, the flow speed of water, and the temperature of water in the inlet are constant, and that the prototype and pipes are wrapped with an insulation layer. Under a balanced state, the temperature in the prototype remains constant (Figure 21B), and thus, the power is also constant.

Under the same initial water temperature and flow speed, the rotation speed of converter is changed from $0 \mathrm{rpm}$ to $3000 \mathrm{rpm}$. Figure 22 shows the measured and calculated curves of power and temperature. The measured and calculated values of the actual thermal powers are nearly the same (Figure 22B). However, the calculated values of the initial thermal power are higher than the measured values, and the deviation between them increases as speed increases (Figure 22A). 


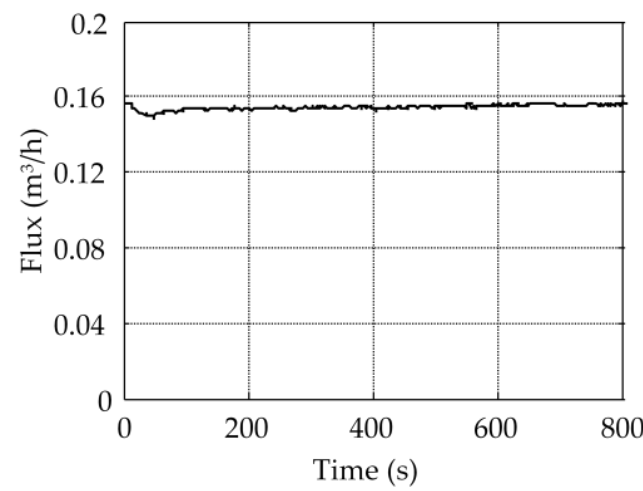

(A)

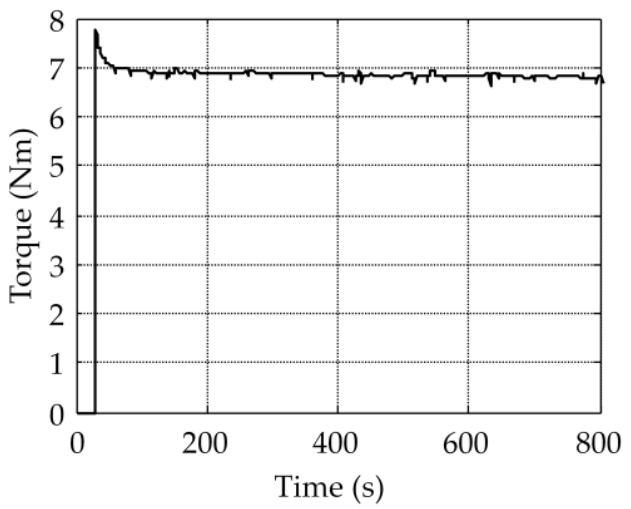

(C)

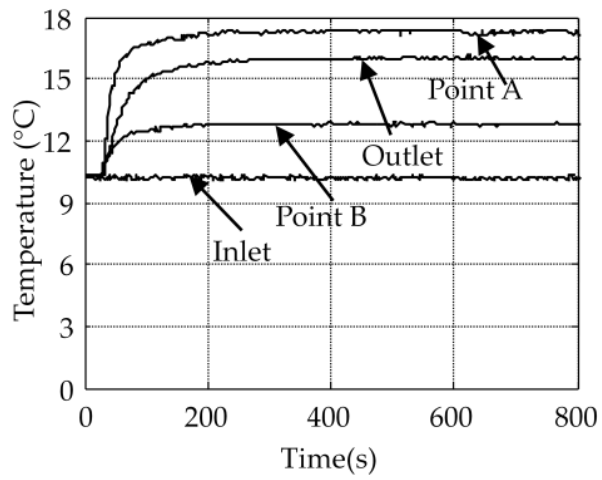

(B)

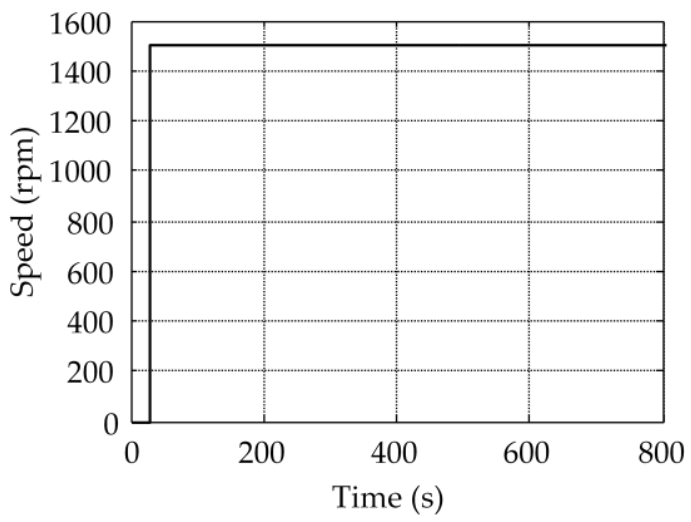

(D)

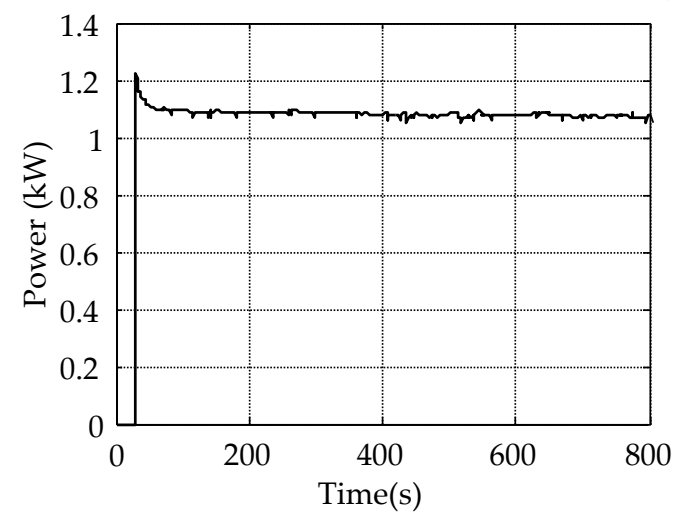

(E)

Figure 21. Measured curves: (A) flow flux; (B) temperature; (C) torque; (D) rotation speed; and (E) thermal power.

Measuring the real initial thermal power is actually impossible because the temperature changes as soon as the converter starts operating. Nevertheless, we assume that when converter achieves constant speed, its temperature will not change because the acceleration time of the motor is extremely short. We also deem that the measured power at the moment when the converter achieves constant speed is actually the initial thermal power. When speed is higher, the acceleration time is longer, and thermal power is also higher. The temperature increase in the converter will be higher because of these two factors, and thus, the measured initial thermal power is lower than the calculated value when the speed increases. As shown in Figure 22C, the calculated and measured temperatures of point $\mathrm{A}$ are nearly the same, whereas the calculated temperature of point $B$ is slightly higher than its measured temperature because point $B$ is located near the outer surface of the stator. Even if the converter is 
wrapped with an insulation layer, a small amount of heat from the outer surface of the stator still transmits though the insulation layer and into the surroundings.

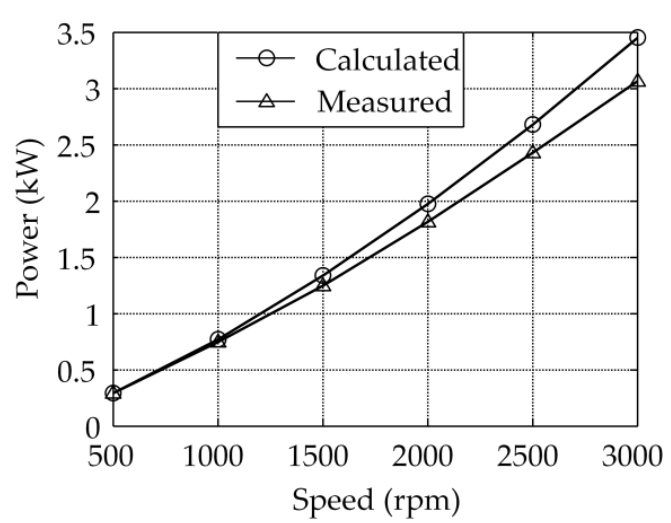

(A)

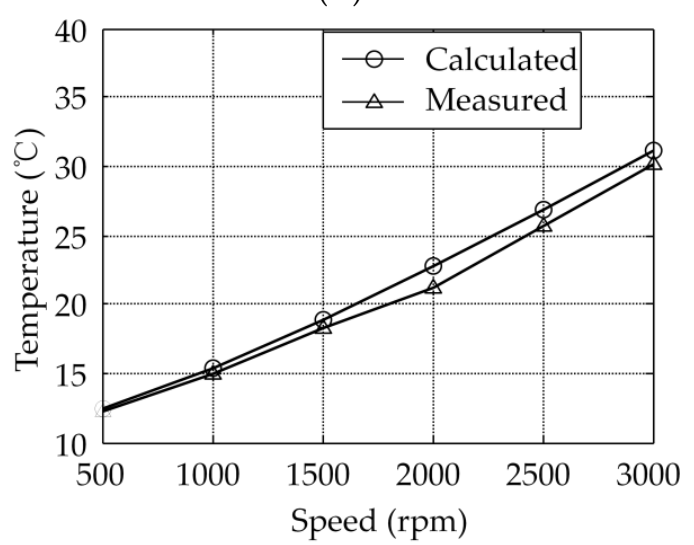

(C)

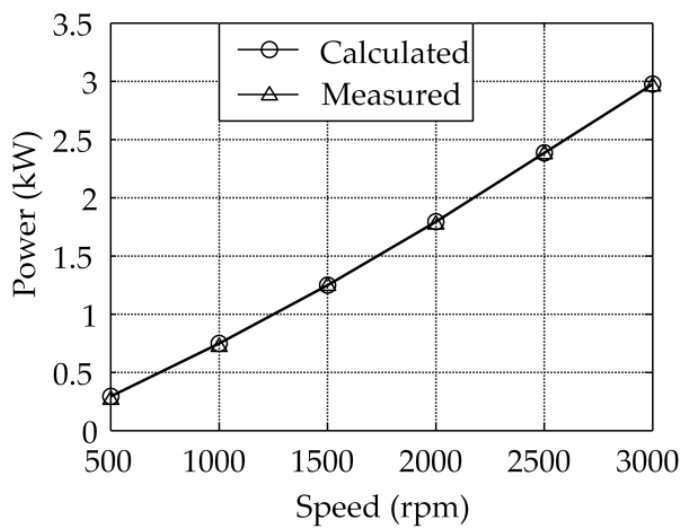

(B)

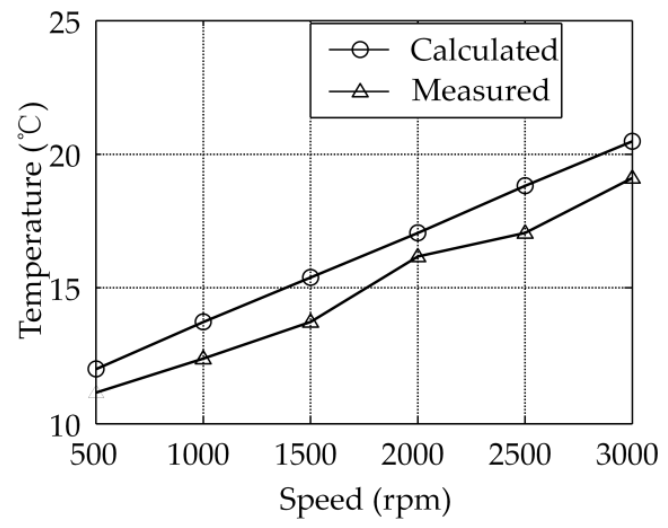

(D)

Figure 22. Comparison of the measured and calculated values of the prototype when flow speed is $0.8 \mathrm{~m} / \mathrm{s}$ : (A) initial thermal power; (B) actual thermal power; (C) temperature of point A; (D) temperature of point $\mathrm{B}$.

Figure 23 indicates the efficiency of the converter at different speeds. Efficiency is extremely high at all the speed, thereby indicating that value of the output thermal power is closed to that of the input thermal power. This result proves the feasibility of the assumption that no heat exchange occurs between the converter and its surroundings during temperature calculation. Efficiency is reduced when the speed increases because the thermal power of the converter increases, along with the heat exchange between the converter and its surroundings.

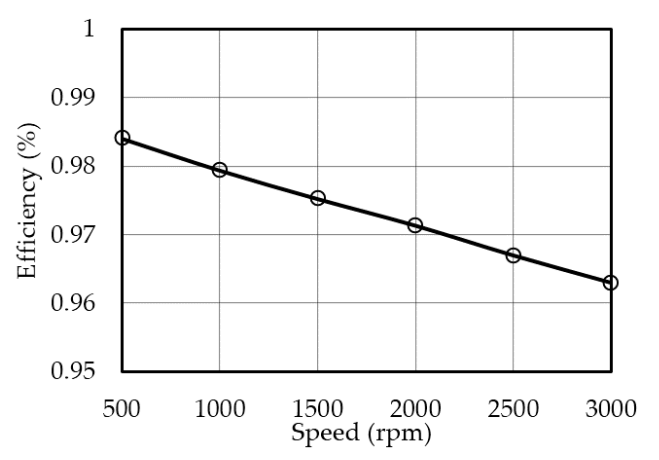

Figure 23. Efficiency of the converter. 


\section{Conclusions}

A novel mechanical to thermal power converter is presented in this study. The converter can convert all forms of input energy (e.g., electrical, wind, hydraulic and other types of mechanical energy) directly into heat energy. The results of the calculation and experiment performed in this study prove the correctness and feasibility of the proposed converter.

The thermal power of the converter is mainly eddy current thermal power in the stator based on the calculation and analysis results. The decreasing rate between the initial and actual power values indicates the heat exchange performance of the converter. The converter operates at a low rotation speed and at a high flow speed of water will achieve a low decreasing rate, thereby indicating a high power density and a low temperature increase in the converter. The characteristic curves of the actual thermal power and water temperature increase indicate the control feature of the converter. The output power of the converter is approximately constant when flow speed and rotation speed are low. This work provides effective calculation, analytical, and experimental methods for the proposed converter. Furthermore, it presents the basic mechanism and the operation characteristic of this converter. On the basis of the results, further research on the converter will be developed.

Acknowledgments: This work was supported by National Natural Science Foundation of China (NSFC) No. 51407046 and Natural Science Foundation of Heilongjiang Province, China No. E2015008.

Author Contributions: Lei Chen did most of the calculation, analysis, experiment and paper writing. Yulong Pei did the analysis of distribution of eddy current. Feng Chai made contributions on experiment. Shukang Cheng did the manufacture of the prototype.

Conflicts of Interest: The authors declare no conflict of interest.

\section{References}

1. Oh, J.-H.; Nam, Y. Study on the Effect of Ground Heat Storage by Solar. Heat Using Numerical Simulation. Energies 2015, 8, 13609-13627. [CrossRef]

2. International Energy Agency (IEA). World Energy Outlook 2013; IEA: Paris, France, 2013.

3. Moretti, E.; Bonamente, E.; Buratti, C.; Cotana, F. Development of Innovative Heating and Cooling Systems Using Renewable Energy Sources for Non-Residential Buildings. Energies 2013, 6, 5114-5129. [CrossRef]

4. Tchapda, A.H.; Pisupati, S.V. A Review of Thermal Co-Conversion of Coal and Biomass/Waste. Energies 2014, 7, 1098-1148. [CrossRef]

5. Valanciusemail, R.; Jurelionis, A.; Dorosevas, V. Method for cost-benefit analysis of improved indoor climate conditions and reduced energy consumption in office buildings. Energies 2013, 6, 4591-4606. [CrossRef]

6. Pisello, A.L.; Cotana, F.; Nicolini, A.; Brinchi, L. Development of clay tile coatings for steep-sloped cool roofs. Energies 2013, 6, 3637-3653. [CrossRef]

7. Buratti, C.; Moretti, E. Glazing systems with silica aerogel for energy savings in buildings. Appl. Energy 2012, 98, 396-403. [CrossRef]

8. Agemar, T.; Weber, J.; Schulz, R. Deep Geothermal Energy Production in Germany. Energies 2014, 7, 4397-4416. [CrossRef]

9. Cheng, M.; Sun, L.; Buja, G.; Song, L. Advanced Electrical Machines and Machine-Based Systems for Electric and Hybrid Vehicles. Energies 2015, 8, 9541-9564. [CrossRef]

10. Chu, W.Q.; Zhu, Z.Q.; Liu, X.; Stone, D.A.; Foster, M.P. Iron loss calculation in permanent magnet machines under unconventional operations. IEEE Trans. Magn. 2014, 50, 1-4. [CrossRef]

11. Zhao, J.; Liu, W.; Li, B.; Liu, X.; Gao, C.; Gu, Z. Investigation of Electromagnetic, Thermal and Mechanical Characteristics of a Five-Phase Dual-Rotor Permanent-Magnet Synchronous Motor. Energies 2015, 8, 9688-9718. [CrossRef]

12. Choi, J.; Kim, S.-K.; Kim, K.; Park, M.; Yu, I.-K.; Kim, S.; Sim, K. Design and Performance Evaluation of a Multi-Purpose HTS DC Induction Heating Machine for Industrial Applications. IEEE Trans. Appl. Supercond. 2015, 25, 1-5. [CrossRef] 
13. Araneo, R.; Dughiero, F.; Fabbri, M.; Forzan, M.; Geri, A.; Morandi, A.; Lupi, S.; Ribani, P.L.; Veca, G. Electromagnetic and thermal analysis of the induction heating of aluminum billets rotating in DC magnetic field. COMPEL 2008, 27, 467-479.

14. Fabbri, M.; Morandi, A.; Negrini, F. Temperature Distribution in Aluminum Billets Heated by Rotation in Static Magnetic Feld Produced by Superconducting Magnets. COMPEL 2005, 24, 281-290. [CrossRef]

15. Fabbri, M.; Morandi, A.; Ribani, P.L. DC Induction Heating of Aluminum Billets Using Superconducting Magnets. COMPEL 2008, 27, 480-490.

16. Fabbri, M.; Forzan, M.; Lupi, S.; Morandi, A.; Ribani, P.L. Experimental and Numerical Analysis of DC Induction Heating of Aluminum Billets. IEEE Trans. Magn. 2009, 45, 192-200. [CrossRef]

17. Magnusson, N.; Bersås, R.; Runde, M. Induction Heating of Aluminum Billets Using HTS DC Coils. Inst. Phys. Conf. Ser. 2004, 181, 1104-1109.

18. Morandi, A.; Fabbri, M.; Ribani, P.L. Design of a Superconducting Saddle Magnet for DC Induction Heating of Aluminum Billets. IEEE Trans. Appl. Supercond. 2008, 18, 816-819. [CrossRef]

19. Lubin, T.; Netter, D.; Leveque, J.; Rezzoug, A. Induction Heating of Aluminum Billets Subjected to a Strong Rotating Magnetic Field Produced by Superconducting Windings. IEEE Trans. Magn. 2009, 45, 2118-2127. [CrossRef]

20. Watanabe, T.; Todaka, T.; Enokizono, M. Analysis of a New Induction Heating Device by Using Permanent Magnets. IEEE Trans. Magn. 2005, 41, 1884-1887. [CrossRef]

21. Dabala, K. Analysis of mechanical losses in three-phase squirrel-cage induction motors. In Proceedings of the Fifth International Conference on Electrical Machines and Systems (ICEMS 2001), Shenyang, China, 18-20 August 2001.

22. Lei, C.; Feng, C.; Yulong, P.; Shukang, C. The Solution of the 3D Electromagnetic Equation and Research on Related Electromagnetic Parameters of the Novel Rotational Electromagnetic Heating Machine. Trans. China Electrotechn. Soc. 2011, 26, 147-153.

23. Huppunen, J. High-Speed Solid-Rotor Induction Machine Electromagnetic Calculation and Design. Ph.D. Thesis, Lappeenranta University of Technology, Lappeenranta, Finland, 3 December 2004.

24. Zhu, Z.Q.; Ng, K.; Schofield, N.; Howe, D. Improved Analytical Modeling of Rotor Eddy Current loss in Brushless Machines Equipped with Surface Mounted Permanent Magnets. IEE Proc. Elect Power Appl. 2004, 151, 641-650. [CrossRef]

25. Stranges, N. An Investigation of Iron Losses Due to Rotating Flux in Three Phase Induction Motor Cores. Ph.D. Thesis, McMaster University, Hamilton, ON, Canada, 2000.

26. Shikun, C. Design of Electrical Machines; China Machine Press: Beijing, China, 2002; pp. 76-77.

27. Ionel, D.M.; Popescu, M.; Dellinger, S.J. On the Variation with Flux and Frequency of the Core Loss Coefficients in Electrical Machines. IEEE Trans. Magn. 2006, 42, 658-667. [CrossRef]

28. Ravnik, J.; Hriberšek, M.; Škerget, L. Coupled BEM-FEM analysis of flow and heat transfer over a solar thermal collector. Eng. Anal. Bound. Elem. 2014, 45, 20-28. [CrossRef]

29. Ishak, D.; Zhu, Z.Q.; Howe, D. Eddy Current Loss in the Rotor Magnets of Permanent-magnets Brushless Machines Having a Fractional Number of Slots per Pole. IEEE Trans. Magn. 2005, 41, 2462-2469. [CrossRef]

(C) 2016 by the authors; licensee MDPI, Basel, Switzerland. This article is an open access article distributed under the terms and conditions of the Creative Commons Attribution (CC-BY) license (http://creativecommons.org/licenses/by/4.0/). 